\title{
Uterine arteriovenous malformation - diagnosis and management
}

\author{
Agata Szpera-Goździewicz, Karolina Gruca-Stryjak, Grzegorz H. Bręborowicz, \\ Mariola Ropacka-Lesiak
}

Department of Perinatology and Gynecology, Poznan University of Medical Sciences, Poznan, Poland

\begin{abstract}
Uterine arteriovenous malformations are uncommon but potentially life-threatening conditions. They can be congenital or acquired and should be suspected in cases of severe or persistent uterine bleeding. In recent years, there has been an increasing number of reports of acquired vascular lesions of the uterus following pregnancy, abortion, caesarean delivery and curettage. This paper presents the review of the literature considered epidemiology, pathophysiology, diagnostic methods and treatment options. Unexplained uterine bleeding should be always an indication for colour Doppler ultrasonography and the presence of arteriovenous malformation should be always excluded.
\end{abstract}

Key words: uterine arteriovenous malformation, abnormal vaginal bleeding, dilatation and curettage, Doppler ultrasound

Ginekologia Polska 2018; 89, 5: 276-279

\section{INTRODUCTION}

Arteriovenous malformations (AVMs) are rare but considered potentially life-threatening due to profuse or irregular bleeding from abnormal vascular connections [1]. The prevalence of uterine AVM is unknown, as only about 100 cases have been reported in the literature [2]. However, reported cases are on the rise because of the increasing availability of imaging modalities like ultrasound, computed tomography $(\mathrm{CT})$, and magnetic resonance imaging (MRI). Accurate clinical and radiological diagnosis is essential, because the uterine instrumentation that is often used for management of abnormal bleeding, can lead to massive haemorrhage. The initial imaging modality of choice for AVM is sonography with colour and spectral Doppler analysis. The diagnosis is based on the presence of hypoechoic sinuous spaces in the myometrium demonstrating vascular flow [3].

\section{Classification and symptoms}

Pregnancy-related complications are the most common cause of abnormal uterine bleeding in women of reproductive age. AVMs are one of the rare causes for abnormal uterine bleeding. They are classified into congenital and acquired, of which acquired AVMs are more common [1, 4].
Congenital AVM develop due to failure in embryological differentiation of primitive vascular structures, resulting in the creation of abnormal vascular connection [5]. Histologic examination of these malformations reveals many thin-walled capillary vessels intertwining with the vessels in the myometrium. Congenital AVM tend to extend beyond the margins of the uterus into the pelvis, with frequent feeders from pelvic vessels other than the uterine artery. These lesions have been predominantly reported in women of reproductive age, but very rarely in women who have never been pregnant [6]. Acquired AVMs are distinguished by multiple connections of varying size between the arteries and veins in the same proximity $[6,7]$. Histologic examination reveals multiple small arteriovenous fistulae between the intramural arterial branches and the myometrial venous plexuses [4].

Acquired AVMs are predominantly related to various forms of iatrogenic uterine trauma, e.g., D\&C or uterine surgery (cesarean section, myomectomy); even normal vaginal delivery could be traumatic enough to stimulate the formation of AVMs. Less commonly, AVMs can be triggered by trophoblastic disease, endometrial carcinoma, cervical carcinoma, and infections $[1,8,9]$. Past medical history is 
important in patients complaining about abnormal uterine bleeding and may suggest the probability of uterine AVM. Affected patients may have a wide sp ectrum of clinical signs. Some patients may be asymptomatic, while others may present with a range of symptoms such as menorrhagia and menometrorrhagia after miscarriage, uterine surgery, or D\&C; lower abdominal pain; dyspareunia; and anaemia $[3,10]$. Severe AVM may lead to cardiovascular repercussions with symptoms of dyspnoea, fatigue, and heart decompensation [6]. In 30\% of patients, blood transfusion is necessary [11].

\section{Diagnosis}

Traditionally, AVM has been diagnosed using laparotomy or histopathological examination of the uterus after hysterectomy. The initial imaging modality of choice for uterine AVM is ultrasonography with colour and spectral Doppler analysis, which significantly increases its sensitivity. Visualization of the vascular nature of anechoic myometrial lesion is very helpful [6]. It also helps in ruling out other problems causing abnormal uterine bleeding like rPOC, GTD, sarcoma of the uterus, uterine artery pseudoaneurysm, and pelvic varicose veins. It has been recently suggested that all patients showing a hypervascular lesion in the myometrium must undergo a work-up for rPOC. We would like to focus on the fact that in normal pregnancy, due to vasodilatation and decreasing resistance in the spiral arteries, a hypervascular appearance with turbulent flow is visible in the myometrium, where implantation takes place [12]. The hypervascularity and turbulence within the myometrium does not immediately disappear following spontaneous or induced abortion. The regression period can be prolonged in the presence of rPOC or molar pregnancy $[13,14]$. Timmerman et al. describe two types of acquired uterine AVM following pregnancy: true AVM and subinvolution of the placental bed [15].

Ultrasonography, as a valuable, fast, easy to perform, cheap and non-invasive procedure, is becoming a preferred method for diagnosing AVM. Grey scale ultrasound of uterine AVM commonly shows heterogeneous nonspecific spaces in the myometrium, multiple cystic lesions, and tubular anechoic areas concomitant with a normal endometrium $[2,16]$ (Fig. 1A). The most common colour Doppler imaging findings are reported to be hypervascularity within the lesion, turbulent flow, and multiple tortuous feeding vessels [2] (Fig. 1B, Fig. 2). Spectral Doppler ultrasound shows low resistance index values and pulsatility index with high peak systolic velocity flow (PSV) [16]. In normal myometrium, the signal presents as PSV of $9-44 \mathrm{~cm} / \mathrm{s}$ and RI of $0.6-0.8$, whereas the systolic and diastolic velocities are 4 to 6 times higher in case of uterine AVM. Timmerman et al. showed that PSV could differentiate between safe and potentially

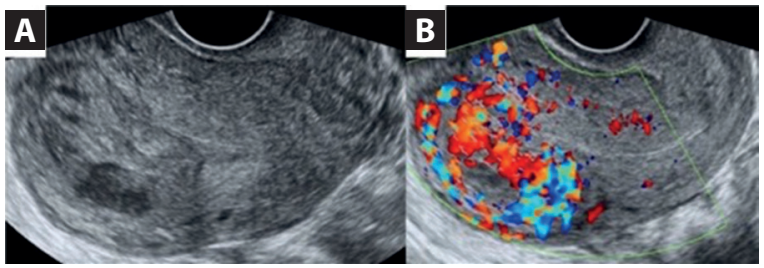

Figure 1. A. Transvaginal ultrasound of bulky uterus with heterogeneous myometrium. Pay attention to the posterior wall of the uterus with an abnormal appearance of the myometrium. B. Ultrasound color Doppler shows increased vascularity and multidirectional flow within posterior wall and fundus of the uterus

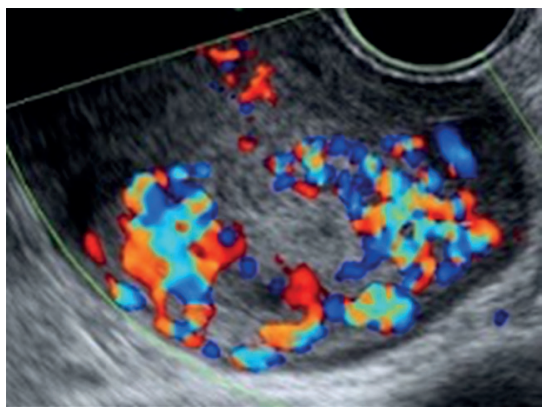

Figure 2. Transvaginal colour Doppler ultrasound image of multiple vascular channels within myometrium showing colored mosaic pattern which may suggest arteriovenous malformation

dangerous AVM [3]. Vascular malformation with a PSV value of $0.83 \mathrm{~m} / \mathrm{s}$ were considered potentially dangerous; these cases required immediate embolization. PSV values ranging from 0.39 to 0.83 usually indicate less dangerous vascular malformation. Conversely, PSV values $<0.39 \mathrm{~m} / \mathrm{s}$ were labelled as safe [3]. Therefore, Doppler examination should be performed before a $\mathrm{D} \& \mathrm{C}$, since this procedure in women with AVM is likely to worsen the bleeding. This may result in life-threating haemorrhage, which may also necessitate a hysterectomy. Furthermore, ultrasonography has been used to assess the effectiveness of embolization 24 hours after the procedure and to select the patients who require repeat embolization [4].

Digital subtraction angiography is the gold standard technique for diagnosing uterine AVM. Angiographic analysis may reveal bilateral uterine artery hypertrophy that feed a tortuous, hypertrophic arterial mass with large accessory feeding vessels as well as early drainage into enlarged, hypertrophic veins during the arterial phase [17]. This invasive technique allows for the confirmation of diagnosis and helps identify the leading feeder vessels when embolization may be indicated as a treatment option [18].

Magnetic resonance (MR) allows for the accurate diagnosis of AVM due to best soft tissue characterization, multiplanar imaging capabilities, and the use of gadolinium-based contrast media [19]. MRI with gadolinium contrast media shows a hypervascular arterial-dominant flow and allows 
for the accurate evaluation of vascular supply and drainage. Typical features of the AVM in MRI include a bulky uterus, with a focal mass, disruption of the junctional zones, multiple serpiginous flow-related signal voids in the myometrium with intense enhancement in post-contrast images, and prominent parametrial vessels $[17,20]$. MRI also provides detailed visualization of the anatomy and the relation of the AVM with the surrounding structures [20]. The main disadvantages of MRI are its high cost, limited availability in some countries, and relatively long time of acquisition (e.g. when compared to CT angiography).

The role of three-dimensional CT is to define the extent of involvement, to rule out extrauterine involvement, to differentiate between congenital and acquired uterine AVM, and to identify the feeding vessels or uterine arteries [7, 21]. CT angiography reduces the radiation dose, study time, and contrast required to perform the procedure in patients planned for embolization. In patients scheduled to undergo surgery, it could be useful for orient the surgeon to the anatomy [22]. CT angiography is preferred in unstable patients with heavy bleeding or those who have contraindications for undergoing MRI [7].

Hysteroscopy has also been used to diagnose AVM, but its value is limited [11]. However, it could be valuable for AVM diagnosis that it is localized just beneath the endometrium.

Nowadays, angiography is usually used for planned therapeutic embolization or before surgical management, whereas ultrasound examination is becoming a preferred diagnostic tool for AVM. Many authors do not recommend performing angiography in all patients with a hypervascular uterine lesion as a rule [23].

\section{Treatment}

Since most women with AVM are of childbearing age and present with coexisting excessive vaginal bleeding, it is difficult to propose the appropriate treatment.

Uterine artery embolization is considered the first line treatment for women with recurrent episodes of bleeding, with severe bleeding or for hemodynamically unstable patients who wish to preserve fertility $[15,24]$. The eligibility of patients for embolization is based on the clinical condition; the size of the AVM in imaging studies does not correlate with the need for embolization. This procedure is highly effective, safe, and has a low risk of complications; however, some cases may require to repeat embolization $[2,17,24,25]$. The possible side effects are low-grade fever, pain, infection, transient buttock and lower limb claudication, perineal skin sloughing, uterovaginal and recto-vesico-vaginal fistulae, and urinary bladder necrosis [26-28]. However, the risk of complications is extremely rare and is minimized when the procedure is performed by an interventional radiology expert. Embolization does not affect the menstrual cycle or pregnancy. Poppe et al. showed normal placental flow on Doppler ultrasound examination in pregnant patients who had previously undergone peIvic embolization [29]. There are no reports of infertility or intrauterine growth restriction following this procedure. It is estimated that uterine AVM has been linked to recurrent pregnancy loss, because of the hypervascularization that may alter the implantation site of the embryo [30]. Owing to the fact that uterine AVMs have a tendency to proliferate during pregnancy, some authors consider the presence of uterine AVM an absolute contraindication for pregnancy [17]. Therefore, young women, who wish to preserve fertility, should be treated by means of angiographic embolization. Various agents such as coils, gelatine sponge, polyvinyl alcohol, detachable balloons, and isobutyl-2-cyanoacrylate have been used for uterine artery embolization; the choice of agent depends on the vessel dimension that needs to be embolized and by whether temporary or permanent occlusion is required [31]. Nowadays, absorbable gelatine sponge pledgets are the material of choice for uterine artery embolization [31]. Uterine artery embolization is the gold standard treatment for curing haemorrhage due to AVM in hemodynamically stable patients.

Hysterectomy remains the treatment of choice in postmenopausal women with AVM, in women who do not wish to preserve fertility, as an emergency procedure in life-threating conditions, or when transcatheter embolization fails [18]. Intrauterine tamponade with a Foley catheter should also be considered in life-threating haemorrhage [4].

Expectant management, oestrogens and progestins, methylergonovine, danazol, 15-methyl-prostaglandin F2alpha, oral contraceptive pills, intramuscular and subsequent oral methylergonovine maleate, intravenous conjugated oestrogens with oral methylergometrine maleate, and intrauterine contraceptive devices have been found to be useful in hemodynamically stable patients with single or few episodes of vaginal bleeding and have shown to be associated with regression of lesions, based on ultrasound examination $[11,15,32,33]$.

There are other less frequently used surgical methods, such as the coagulation of AVM under hysteroscopic guidance, laparoscopic bipolar coagulation of uterine vessels, surgical removal of the AVM, and uterine artery ligation $[9,11,34]$. Because of the risk of spontaneous rupture of the subserosal type uterine AVM, some authors indicate the surgical removal of this type of lesion as a treatment of choice [35].

\section{CONCLUSIONS}

Unexplained uterine bleeding should be always an indication for colour Doppler ultrasonography. Vascular lesions of the uterus may be more common than formerly 
thought. Usually, AVMs are present in young women, with a previous history of spontaneous abortion with D\&C of the uterus. Definitely, three-dimensional CT angiography helps in confirming the diagnosis. In some cases of AVMs uterine artery embolization is effective in treatment. Care must be taken while diagnosing AVM after miscarriage. These patients should be first evaluated for rPOC with monitoring of beta-hCG levels but the presence of AVM should be always excluded

\section{Acknowledgments}

None.

\section{REFERENCES}

1. Hoffman MK, Meilstrup JW, Shackelford DP, et al. Arteriovenous malformations of the uterus: an uncommon cause of vaginal bleeding. Obstet Gynecol Surv. 1997; 52(12): 736-740, doi: 10.1097/00006254-19971200000004, indexed in Pubmed: 9408929.

2. Peitsidis $\mathrm{P}$, Manolakos E, Tsekoura V, et al. Uterine arteriovenous malformations induced after diagnostic curettage: a systematic review. Arch Gynecol Obstet. 2011; 284(5): 1137-1151, doi: 10.1007/s00404-0112067-7, indexed in Pubmed: 21904854.

3. Timmerman D, Wauters J, Van Calenbergh S, et al. Color Doppler imaging is a valuable tool for the diagnosis and management of uterine vascular malformations. Ultrasound Obstet Gynecol. 2003; 21(6): 570-577, doi: 10.1002/uog.159, indexed in Pubmed: 12808674.

4. O'Brien P, Neyastani A, Buckley AR, et al. Uterine arteriovenous malformations: from diagnosis to treatment. J Ultrasound Med. 2006; 25(11): 1387-92; quiz 1394, doi: 10.7863/jum.2006.25.11.1387, indexed in Pubmed: 17060424.

5. Kasznica J, Nisar N. Congenital vascular malformation of the uterus in a stillborn: a case report. Hum Pathol. 1995; 26(2): 240-241, doi: 10.1016/0046-8177(95)90043-8, indexed in Pubmed: 7860055.

6. Vijayakumar A, Srinivas A, Chandrashekar BM, et al. Uterine vascular lesions. Rev Obstet Gynecol. 2013; 6(2): 69-79, indexed in Pubmed: 24340126.

7. Aiyappan SK, Ranga U, Veeraiyan S. Doppler Sonography and 3D CT Angiography of Acquired Uterine Arteriovenous Malformations (AVMs): Report of Two Cases. J Clin Diagn Res. 2014; 8(2): 187-189, doi: 10.7860/JCDR/2014/6499.4056, indexed in Pubmed: 24701531.

8. Clarke JA, Viswanatha RK, Hamid R, et al. Diagnosis and management of life-threatening hypermenorrhagia caused by uterine arteriovenous malformation secondary to surgical termination of pregnancy: video evidence! BMJ Case Rep. 2012; 2012, doi: 10.1136/bcr-2012-007368, indexed in Pubmed: 23213129.

9. Fleming $\mathrm{H}$, Ostör AG, Pickel $\mathrm{H}$, et al. Arteriovenous malformations of the uterus. Obstet Gynecol. 1989; 73(2): 209-214, indexed in Pubmed: 2643064.

10. Brown JV, Asrat T, Epstein HD, et al. Contemporary diagnosis and management of a uterine arteriovenous malformation. Obstet Gynecol. 2008; 112(2 Pt 2): 467-470, doi: 10.1097/AOG.0b013e3181719f7d, indexed in Pubmed: 18669767.

11. Manolitsas T, Hurley V, Gilford E. Uterine arteriovenous malformation-a rare cause of uterine haemorrhage. Aust N Z J Obstet Gynaecol. 1994; 34(2): 197-199, doi: 10.1111/j.1479-828x.1994.tb02691.x, indexed in Pubmed: 7980314.

12. Laing $F$, Frates $M$, Frates $M$. Ultrasound evaluation during the first trimester of pregnancy. In: Callen PW. ed. Ultrasonography in obstetrics and gynecology. 4th ed., Philadelphia 2000: Philadelphia.

13. Dillon EH, Case CQ, Ramos IM, et al. Endovaginal US and Doppler findings after first-trimester abortion. Radiology. 1993; 186(1): 87-91, doi: 10.1148/radiology.186.1.8416592, indexed in Pubmed: 8416592.

14. Kido A, Togashi K, Koyama T, et al. Retained products of conception masquerading as acquired arteriovenous malformation. J Comput Assist Tomogr. 2003; 27(1): 88-92, doi: 10.1097/00004728-200301000-00016, indexed in Pubmed: 12544249.
15. Timmerman D, Van den Bosch $\mathrm{T}$, Peeraer $\mathrm{K}$, et al. Vascular malformations in the uterus: ultrasonographic diagnosis and conservative management. Eur J Obstet Gynecol Reprod Biol. 2000; 92(1): 171-178, doi: 10.1016/s0301-2115(00)00443-7, indexed in Pubmed: 10986453.

16. Maldonado J, Perez C, Rodriguez W. AJR Teaching File: Profuse vaginal bleeding seven weeks following induced abortion. AJR Am J Roentgenol. 2008; 191(6 Suppl): S79-S82, doi: 10.2214/AJR.07.7044, indexed in Pubmed: 19018054.

17. Grivell RM, Reid KM, Mellor A. Uterine arteriovenous malformations: a review of the current literature. Obstet Gynecol Surv. 2005; 60(11): 761-767, doi: 10.1097/01.ogx.0000183684.67656.ba, indexed in Pubmed: 16250925.

18. Vogelzang RL, Nemcek AA, Skrtic Z, et al. Uterine arteriovenous malformations: primary treatment with therapeutic embolization. J Vasc Interv Radiol. 1991; 2(4): 517-522, doi: 10.1016/s1051-0443(91)72234-3, indexed in Pubmed: 1797218.

19. Alessandrino F, Di Silverio E, Moramarco LP. Uterine arteriovenous malformation. J Ultrasound. 2013; 16(1): 41-44, doi: 10.1007/s40477013-0007-z, indexed in Pubmed: 24046800.

20. Bhoil R, Raghuvanshi V, Basavaiah S. A case of congenital uterine arterio-venous malformation managed by hysterectomy. Pol J Radiol. 2015; 80: 202-205, doi: 10.12659/PJR.893299, indexed in Pubmed: 25922626.

21. Wani NA, Shaheen F, Kousar T, et al. Uterine arteriovenous malformation diagnosed with multislice computed tomography: a case report. J Reprod Med. 2010; 55(3-4): 166-170, indexed in Pubmed: 20506681.

22. Gulati MS, Paul SB, Batra A, et al. Uterine arteriovenous malformations: the role of intravenous 'dual-phase' $\mathrm{CT}$ angiography. Clin Imaging. 2000; 24(1): 10-14, doi: 10.1016/s0899-7071(00)00155-8, indexed in Pubmed: 11120411 .

23. Hashim H, Nawawi O. Uterine arteriovenous malformation. Malays J Med Sci. 2013; 20(2): 76-80, indexed in Pubmed: 23983582.

24. Elia G, Counsell C, Singer SJ. Uterine artery malformation as a hidden cause of severe uterine bleeding. A case report. J Reprod Med. 2001; 46(4): 398-400, indexed in Pubmed: 11354845.

25. Maleux G, Timmerman D, Heye $S$, et al. Acquired uterine vascular malformations: radiological and clinical outcome after transcatheter embolotherapy. Eur Radiol. 2006; 16(2): 299-306, doi: 10.1007/s00330005-2799-5, indexed in Pubmed: 15977019.

26. Lim AKP, Agarwal R, Seckl MJ, et al. Embolization of bleeding residual uterine vascular malformations in patients with treated gestational trophoblastic tumors. Radiology. 2002; 222(3):640-644, doi: 10.1148/radiol.2223010035, indexed in Pubmed: 11867779.

27. Hare WS, Holland CJ. Paresis following internal iliac artery embolization Radiology. 1983; 146(1): 47-51, doi: 10.1148/radiology.146.1.6849068, indexed in Pubmed: 6849068.

28. Chen Y, Wang G, Xie F, et al. Embolization of uterine arteriovenous malformation. Iran J Reprod Med. 2013; 11(2): 159-166, indexed in Pubmed: 24639742.

29. Poppe W, Van Assche FA, Wilms G, et al. Pregnancy after transcatheter embolization of a uterine arteriovenous malformation. Am J Obstet Gynecol. 1987; 156(5): 1179-1180, doi: 10.1016/0002-9378(87)90136-0, indexed in Pubmed: 3578434.

30. Gopal M, Goldberg J, Klein TA, et al. Embolization of a uterine arteriovenous malformation followed by a twin pregnancy. Obstet Gynecol. 2003; 102(4): 696-698, doi: 10.1097/00006250-200310000-00010, indexed in Pubmed: 14550998.

31. Vedantham S, Goodwin SC, McLucas B, et al. Uterine artery embolization: an underused method of controlling pelvic hemorrhage. Am J Obstet Gynecol. 1997; 176(4): 938-948, doi: 10.1016/s0002-9378(97)70624-0, indexed in Pubmed: 9125624.

32. Khatree $\mathrm{MH}$, Titiz $\mathrm{H}$. Medical treatment of a uterine arteriovenous malformation. Aust N Z J Obstet Gynaecol. 1999; 39(3): 378-380, doi: 10.1111/j.1479-828x.1999.tb03424.x, indexed in Pubmed: 10554961.

33. Ghosh TK. Arteriovenous malformation of the uterus and pelvis. Obstet Gynecol. 1986; 68(3 Suppl): 40S-43S, indexed in Pubmed: 3737074.

34. Milingos $D$, Doumplis $D$, Sieunarine $K$, et al. Uterine arteriovenous malformation: fertility-sparing surgery using unilateral ligation of uterine artery and ovarian ligament. Int J Gynecol Cancer. 2007; 17(3): 735-737, doi: 10.1111/j.1525-1438.2007.00884.x, indexed in Pubmed: 17367327.

35. Seo KJ, Kim J, Sohn InS, et al. Failed transarterial embolization of subserosal uterine arteriovenous malformation. Obstet Gynecol Sci. 2013; 56(5): 333-337, doi: 10.5468/ogs.2013.56.5.333, indexed in Pubmed: 24328024. 